\title{
Efficacy of natural formulations in bovine mastitis pathology: alternative solution to antibiotic treatment
}

\author{
Claudia Pașca ${ }^{1}$, Liviu Alexandru Mărghitaș ${ }^{1}$, Daniel Severus Dezmirean ${ }^{1}$, \\ Ioana Adriana Matei ${ }^{2 凶}$, Victorița Bonta ${ }^{3}$, Ioan Pașca ${ }^{4}$, Flore Chirilă ${ }^{2}$, \\ Adrian Cîmpean ${ }^{4}$, Nicodim Iosif Fiț $^{2}$ \\ ${ }^{1}$ Department of Apiculture and Sericulture, Faculty of Animal Science and Biotechnologies, \\ ${ }^{2}$ Department of Microbiology, ${ }^{4}$ Department of Animal Production and Food Safety, \\ Faculty of Veterinary Medicine, \\ ${ }^{3}$ Life Science Institute "King Michael I of Romania", \\ University of Agricultural Sciences and Veterinary Medicine, Cluj-Napoca, 400372, Romania \\ matei.ioana@usamvcluj.ro
}

Received: March 19, 2020 Accepted: October 5, 2020

\begin{abstract}
Introduction: Bovine mastitis is an inflammatory disease of the udder that causes important economic losses in the animal breeding and dairy product industries. Nowadays, the conventional livestock antibiotic treatments are slowly being replaced by alternative treatments. In this context, the main aim of this study was to evaluate the efficacy of natural products in alternative treatment of bovine mastitis. Material and Methods: Two natural formulations with previously suggested in vitro antimicrobial effect were tested in vivo on mastitic cows. Animals with a positive diagnosis for mastitis $(\mathrm{n}=20)$ were divided into three treatment groups: two groups $(\mathrm{n}=8)$ were administered formulations of propolis, alcoholic extracts of Brewers Gold and Perle hops, plum lichen, common mallow, marigold, absinthe wormwood, black poplar buds, lemon balm, and essential oils of oregano, lavender, and rosemary designated R4 and R7 (differing only in the latter being more concentrated) and one group $(\mathrm{n}=4)$ a conventional antibiotic mixture. In vivo efficacy of treatments was evaluated by somatic cell and standard plate counts, the treatment being considered efficacious when both parameters were under the maximum limit. Results: R7 was effective in the most cases, being therapeutically bactericidal in six out of eight cows, while R4 gave good results in three out of eight cows, and conventional antibiotics cured one out of four. Conclusion: These results suggest the possible therapeutic potential of these natural products in bovine mastitis.
\end{abstract}

Keywords: cows, mastitis, alternative treatment, in vivo testing, natural products.

\section{Introduction}

Bovine mastitis is a major infectious disease that causes the largest economic losses in the animal breeding and dairy industries. Negative financial impacts from mastitis on dairy farms were reported in many parts of the world, including the USA, Europe, Australia, and South Africa (23). It is difficult to estimate the losses associated with clinical mastitis, and even more difficult to quantify those associated with the sub-clinical form. In European countries, losses due to mastitis per cow per year are estimated at between 100 and 300 USD equivalent (9). The sizeable economic burden includes the direct costs, namely the cost of treatment (drugs and veterinary fees), discharged milk, labour cost, fatalities, and repeated cases of mastitis, and the indirect repercussions, which are the decrease in milk yield, milk quality changes (compositional changes, poorer hygienic quality of milk, and public health considerations), culling and replacement cost, pre-term drying off, the animal welfare aspect of mastitis, and associated health problems (23).

Although mastitis is a complex disease involving many factors, and technically, the term could be used to describe any udder injury that may result in inflammation, it is generally accepted as a reference to the inflammatory reaction with microorganic causative agents that have grown too abundantly or entered into 
the udder quarter canal and mammary tissue causing an intramammary infection (IMI) (16). Despite the definition of IMI being unclear, mammary gland health is often defined based on its bacteriology (the presence or absence of an IMI) or based on quarter-level or composite somatic cell count (SCC) (27). IMIs are generally detected through milk culturing. This enables the monitoring of udder health and identification of the aetiological agents of the disease and ensures targeted specific antimicrobial therapy (6).

Pathogens causing mastitis may have different origins, being classified according to the source as contagious, environmental, or opportunistic (16). Contagious microorganisms are usually found on the udder or teat surface of infected cows and are the primary source of infection. Staphylococcus aureus is the species most frequently isolated, followed by Streptococcus agalactiae and the less common pathogens such as Corynebacterium bovis and Mycoplasma bovis (16). Environmental pathogens are found in the immediate surroundings of the cow, in the sawdust and bedding, manure, and soil. Bacteria in this classification include streptococcal strains such as Streptococcus dysgalactiae, S. uberis, S. bovis, Enterococcus faecium, and E. faecalis, and coliforms such as Escherichia coli, Klebsiella pneumonia, and Enterobacter aerogenes (16). They cause mastitis if the immune system of the host is compromised or if sanitation and hygiene is not adequately practiced (24). Opportunistic pathogens result in mild forms of mastitis and include coagulase-negative staphylococci (CoNS). These staphylococci may be isolated from milk, are commensal and usually imply a minor immune response in cattle and only cause mild infections. They include $S$. epidermidis, S. saprophyticus, S. simulans, S. chromogenes, S. hyicus, S. warneri, S. sciuri, and S. xylosus $(16,18)$.

Treatment of mastitis usually involves intramammary administration of antibiotics to clear the quarter of the causative organisms. A clinical response must be perceptible within 5-7 days; otherwise, the case is usually considered a therapeutic failure (2). The commercial intramammary antimicrobial products available in Europe contain either single antibiotics such as cephalexin benzathine, cephalonium, cephapirin benzathine, cephazolin, cloxacillin benzathine, or rifaximin, or a mixture of two or three antibiotics. Products combining multiple antibiotics contain oxacillin benzathine and oxacillin sodium, framycetin sulphate and erythromycin stearate, neomycin sulphate and spiramycin, penicillin $\mathrm{G}$ procaine and novobiocin sodium, cloxacillin benzathine and neomycin sulphate, penicillin $\mathrm{G}$ procaine and neomycin sulphate, cloxacillin benzathine and colistin sulphate, or penicillin $G$ procaine, nafcillin and dihydrostreptomycin sulphate $(2,11)$. However, the extensive use of antibiotics in the treatment and control of mastitis is not always effective and develops resistance and consequent nonresponsiveness to antibiotic therapy (7). Other important issues are the possible implications for human health through an increased risk of antibiotic-resistant strains of bacteria emerging that may then enter the food chain and the increased risk of antibiotic residues in milk (29). Related to these risks, there is continuous pressure to reduce the use of antibiotics in the treatment of foodproducing animals and a dramatic increase in organic milk production, which has led to research into finding alternative antimicrobial agents.

Although there are several studies focused on the antimicrobial effects of plant products $(10,22,30)$ or bee products $(1,8,26)$ on pathogens isolated from milk from mastitic cows, there are only few data regarding in vivo testing. In the context of increased multidrug resistance and demand for organic products, the high costs of treating mastitis and of the development of efficient new synthetic drugs, the low manufacturing cost of plant products, and the apparent lack of antimicrobial resistance to these phytochemicals, the aim of this study was to test in vivo two plant-based and propoliscontaining products with previously proven in vitro efficacy (21).

\section{Material and Methods}

Animals and samples. The study was conducted on a dairy farm located in Cluj County $\left(46^{\circ} 44^{\prime} 54^{\prime \prime} \mathrm{N}\right.$ $\left.23^{\circ} 50^{\prime} 0^{\prime \prime} \mathrm{E}\right)$, Transylvanian Plain, Romania, on a herd of 220 local-breed cows (Bălţata Românească) which were five years old and at the second or third calving. All the cows were tested for mastitis using the California mastitis test (CMT) correlated with clinical and subclinical signs. Clinical signs included lack of appetite, reduction in milk quantity, and milk with whey and fibrin clots. Additionally, somatic cell count (SCC) and bacterial cell count (BCC)/standard plate count (SPC) confirmed the diagnosis. Positive results for mastitis were obtained for 20 cows.

Milk sample collection and analysis. Samples were collected using the recommendations of the US National Mastitis Council (19). The udders of the subjects were washed with abundant clean water and wiped with paper towels, and the teats were surfacedisinfected with swabs containing $80 \%$ ethanol. After discarding the first milk stream, approximately $40 \mathrm{~mL}$ of quarter milk was collected into $50 \mathrm{~mL}$ sterilised tubes and stored at $4^{\circ} \mathrm{C}$ until the hygiene analysis was performed in the reference laboratory of the Milk Quality Control Foundation, Cluj-Napoca, in the next hour after collection.

Somatic cell count. The SCC was determined by the fluoro-opto-electronic method on a Fossomatic 90 Mastitis \& Milk Quality Tester/Somatic Cell Counter (Foss, Denmark), according to the HRN ISO 133662:2006 standard (13). A result of 100,000 cells $/ \mathrm{mL}$ was taken to be a low SCC, since this is generally considered to reflect a healthy mammary gland (25). A high SCC was $>200,000$ cells $/ \mathrm{mL}$, as this is a rational threshold for 
the presence of infection (5). The number of mesophilic aerobic bacteria was assessed indirectly based on the number of colonies generated by the cells of the microorganism present in the milk sample.

Standard plate count. The total number of bacteria (BCC) was determined by the flow cytometric method on a BactoScan FC milk bacteria analyser (Foss), according to the ISO 21187:2004 standard (14). The BactoScan analyser was calibrated on the basis of colony number, which was determined by the reference method (counting the colonies of bacteria on a plate as a standard plate count - SPC), according to the HRN ISO 4833:2003 standard (15). For this count, two sterile Petri plates were inoculated by flooding with $1 \mathrm{~mL}$ of milk. One Petri plate was also inoculated with each of at least three decimal dilutions $\left(10^{-1}-10^{-3}\right)$. The prepared plates were incubated at $37^{\circ} \mathrm{C}$ for $48 \mathrm{~h}$. After incubation, plates having a number of colonies ranging from 25 to 250 were chosen for counting and the colony forming unit (CFU) number was calculated considering the dilution for the individual plate. Results were expressed in CFU/mL of milk. A total number of bacteria $>100,000$ cell $/ \mathrm{mL}$ was considered an indication of mastitis.

Microbiological analysis of milk. For the positive animals, the pathogen analysis (genus or species identification) was performed in the Microbiology Laboratory of the University of Agricultural Sciences and Veterinary Medicine in Cluj-Napoca, by cultivation on specific medium (Muller-Hinton, blood and MacConkey agar). Plate incubation was performed at $37^{\circ} \mathrm{C}$ for $24 \mathrm{~h}$ under aerobic conditions (12). After incubation, morphological analysis of colonies and bacterial cells was performed by Gram staining. For each colony, preliminary tests were performed in order to select the type of analytical profile index (API) microgallery.

The microMérieux API germ identification galleries (bioMérieux Inc., USA) are a bacterial classification system based on a series of experiments. They consist of 20,32 or 50 tests, each contained in small reaction tubes that include a nutrient substrate. This system was developed for the rapid identification of clinically relevant species. The interpretation of the results considers which of the tubes gave a positive reaction, and these data are then compiled into a number that is verified with a database containing all known microorganisms.

In order to confirm the identities of the pathogenic bacteria to the species level, Staphylococcus API 20 STAPH, Streptococcus API 20 STREP, and Bacillus API $50 \mathrm{CH}$ were used for the corresponding genera (Table 1).

Bacterial strains were also identified by the VITEK 2 automatic identification system (bioMérieux) (Table 1). The system builds a strain's biochemical profile by interpreting 70-80 tests impregnated on cards. The identification usually takes $3-4 \mathrm{~h}$, being much more accurate and working with a large database according to the standards used (ISO 17025:2017).
The samples were processed following the identification of the bacterial flora, and then were tested for sensitivity to bee and plant natural products as described by Markey et al. (17).

Experimental testing. Different plant extracts, propolis extract and essential oils were incorporated into a natural soft gel mass (Xanthan gum). Eight formulations (R1-R8) were made according to a previous study (21), including aqueous extract of propolis, alcoholic extracts of Brewers Gold and Perle hops, plum lichen, common mallow, marigold, absinthe wormwood, black poplar buds, lemon balm, and essential oil of oregano, lavender, and rosemary. These were tested in vitro separately and compared to seven antibiotics used in mastitis treatment (oxytetracycline, ceftriaxone, gentamicin, penicillin, florphenicol, enrofloxacin, and amoxicillin), also as described in the previous study (21). In that investigation, following the statistical analysis performed with Epi Info 7 software (https://www.cdc.gov/epiinfo), the two products R4 and R7 were observed to exert significant effects on strains isolated from milk from mastitic cows, and these were chosen in the present experiment for in vivo tests. These were administered intramammarily, in $10 \mathrm{~mL}$ volume. Each gel product contains aqueous extract of propolis, alcoholic extracts of Brewers Gold and Perle hops, plum lichen, common mallow, marigold, absinthe wormwood, black poplar buds, lemon balm, and essential oil of oregano, lavender, and rosemary in different concentrations.

The cows diagnosed with clinical and subclinical mastitis $(n=20)$ were separated from healthy ones in another part of the shelter and divided into three groups. Two of the groups ( $n=8$ in each) were treated with the two selected natural biological gels R4 and R7 chosen based on their in vitro antimicrobial activity published in a previous work (21). The two experimental groups were treated every day (morning and evening) for five days with gel administered intramammarily, gel R4 being used on group 1 and gel R7 on group 2. The third group $(\mathrm{n}=4)$ was treated intramammarily with a commercial conventional antibiotic (CA) product containing amoxicillin and clavulanic acid, following the manufacturer's recommendations and indications.

The treatment efficacy was evaluated by SCC and SPC. Five milk samples were collected from each animal before treatment at $0 \mathrm{~h}$; during treatment at $24 \mathrm{~h}$, $48 \mathrm{~h}$ and $72 \mathrm{~h}$ and after the last day of treatment at $120 \mathrm{~h}$.

At the end of the treatment, the two bee and plant natural products' (R4 and R7) effectiveness was confirmed once again in vitro on a selection of predominant bacterial strains identified from the same milk samples (S. intermedius, S. epidermidis, S. hominis, S. aureus, Bacillus spp., and Streptococcus agalactiae).

Statistical analysis. Statistical analysis was performed with Epi Info 7 software. The mean and standard deviation were calculated, and the differences between the averages were analysed using the ANOVA 
test (parametric test for inequality of means), a value of $\mathrm{P}<0.05$ being considered statistically significant.

\section{Results}

Twenty out of 220 cows from the participating farm were diagnosed with mild clinical and subclinical mastitis based on CMT, SCC, SPC and clinical signs. In all cases, only Gram-positive bacteria were detected. In 15 out of 20 cows, one bacterial species was identified, in four cows, co-infection with two species was discovered, and in one cow co-infection with three species was found. In 17 cows, different staphylococci strains were identified. In descending order of prevalence, the strains were $S$. epidermidis (in 11 cows), $S$. aureus (3), S. schleiferi (2), and S. hominis (1). Other identified Gram-positive cocci belonged to the Micrococcus (3), Streptococcus (1), and Aerococcus (1) genera. Gram-positive bacilli were identified in only three samples, being two Bacillus spp. and one Corynebacterium spp. Co-infection was recorded in five cases: two with $S$. schleiferi and Micrococcus spp.; one with $S$. epidermidis and $S$. hominis; another with $S$. aureus and Aerococcus spp.; and the last one with Staphylococcus spp., Micrococcus spp., and Corynebacterium spp.

Table 1. Pathogens identified in normal and mastitic milk

\begin{tabular}{llll}
\hline Identified microorganism & $\begin{array}{l}\text { Gram } \\
+-\end{array}$ & Kit type & Code profile \\
\hline Staphylococcus epidermidis & + & API Staph & 6773151 \\
\hline Staphylococcus aureus & + & API Staph & ATCC 6538P \\
\hline Staphylococcus schleiferi & + & API Staph & 6732553 \\
\hline Staphylococcus hominis & + & API Staph & 6732112 \\
\hline Aerococcus viridans & + & VITEK Identification & 0625703821500211 \\
\hline Aerococcus viridans & + & VITEK Identification & 0625707930700413 \\
\hline Staphylococcus aureus & + & VITEK Identification & 0209610546712053 \\
\hline Bacillus cereus & + & API 50 CHB & 7212 \\
\hline Corynebacterium spp. & + & VITEK Identification & 4407611554521210 \\
\hline Micrococcus spp. & + & VITEK Identification & 0625703050500211 \\
\hline Streptococcus agalactiae & + & VITEK Identification & 0205610554226611 \\
\hline
\end{tabular}

Table 2. First collection of mammary secretion (time 0 ) from cows in experimental in vivo tests

\begin{tabular}{|c|c|c|c|c|}
\hline $\begin{array}{l}\text { Tested } \\
\text { product }\end{array}$ & Patient & $\begin{array}{l}\text { Predominant bacterial species isolated } \\
\text { from milk sample }\end{array}$ & $\mathrm{CFU} / \mathrm{mL}$ & $\mathrm{SCC} / \mathrm{mL}$ \\
\hline \multirow{8}{*}{ 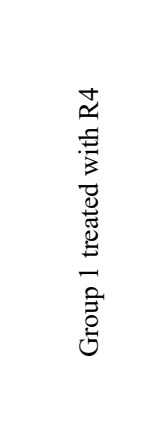 } & 1. & S. epidermidis & 902,000 & 169,800 \\
\hline & 2. & S. epidermidis & 385,000 & $1,000,000$ \\
\hline & 3. & $\begin{array}{l}\text { S. schleiferi, } \\
\text { Micrococcus spp. }\end{array}$ & 89,000 & 114,300 \\
\hline & 4. & $\begin{array}{l}\text { S. schleiferi, } \\
\text { Micrococcus spp. }\end{array}$ & 49,000 & 190,800 \\
\hline & 5. & S. epidermidis & 172,000 & 3,600 \\
\hline & 6. & S. epidermidis & 312,000 & 51,900 \\
\hline & 7. & S. epidermidis & 171,600 & 195,800 \\
\hline & 8. & S. epidermidis & 364,000 & 240,000 \\
\hline \multirow{8}{*}{ 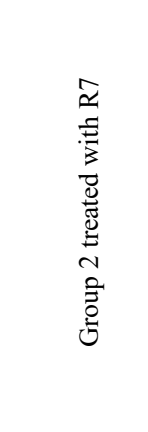 } & 9. & S. epidermidis & 66,000 & 102,100 \\
\hline & 10. & S. epidermidis & 334,000 & 80,300 \\
\hline & 11. & $\begin{array}{l}\text { S. epidermidis, } \\
\text { S. hominis }\end{array}$ & 125,000 & 39,000 \\
\hline & 12. & S. epidermidis & 41,000 & 54,000 \\
\hline & 13. & Bacillus spp. & 48,000 & 105,900 \\
\hline & 14. & S. epidermidis & 37,000 & 10000 \\
\hline & 15. & S. aureus & 177,000 & 129,000 \\
\hline & 16. & Streptococcus spp. & 247,900 & $1,000,000$ \\
\hline \multirow{4}{*}{ 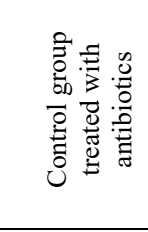 } & 17. & Bacillus spp. & 223,000 & 10,000 \\
\hline & 18. & $\begin{array}{l}\text { S. aureus, } \\
\text { Aerococcus spp. }\end{array}$ & 525,000 & $1,004,600$ \\
\hline & 19. & S. aureus & 218,000 & 12,000 \\
\hline & 20. & $\begin{array}{l}\text { Corynebacterium spp. Staphylococcus } \\
\text { spp. Micrococcus spp. }\end{array}$ & 220,000 & 88,900 \\
\hline
\end{tabular}

$\mathrm{CFU}$ - colony-forming units; SCC - somatic cell count 
Collection of mammary secretions was made before treatment (collection 1) (Table 2), during treatment: at $24 \mathrm{~h}$ (collection 2), $48 \mathrm{~h}$ (collection 3 ), and $72 \mathrm{~h}$ (collection 4), and after the last day of treatment at $120 \mathrm{~h}$ (collection 5). In all treated cows, a decreasing number of bacteria and somatic cells were observed between the first measurement (before treatment) and the last measurement (after the end of treatment). Similarly, the mean number of bacteria $(\mathrm{CFU} / \mathrm{mL})$ in the fifth measurement was statistically significantly lower than the mean from the first measurement in both the group treated with $\mathrm{R} 4$ and the group treated with the commercial product $(\mathrm{P}=0.00841$ and $\mathrm{P}=0.00301$, respectively). In cows treated with $\mathrm{R} 7$, a significant difference $(\mathrm{P}=0.00872)$ was also observed for the fourth measurement (the last made during the treatment) (Fig. 1).

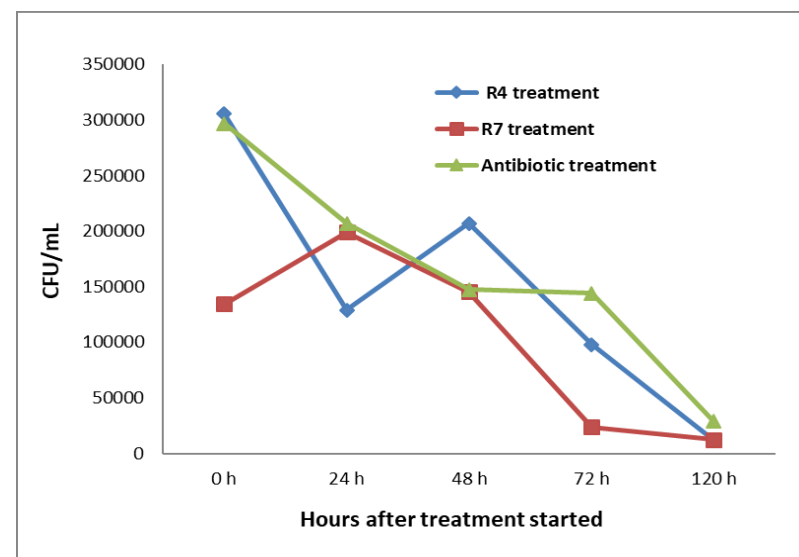

Fig.1. Number of colony-forming units (CFU) in milk from mastitic cows treated with two different natural plant-based formulations and conventional antibiotics

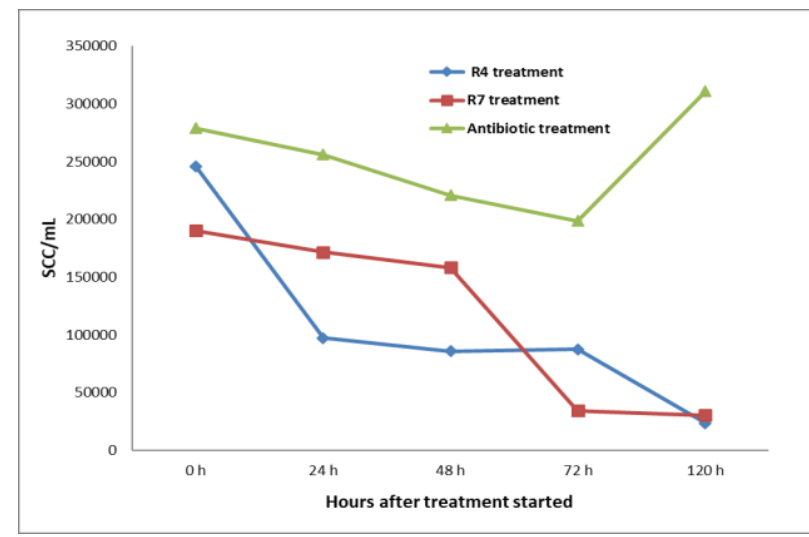

Fig. 2. Somatic cells count (SCC) in quarter milk samples from cows treated with two different natural plant-based formulations and conventional antibiotics

Among the cows treated with $\mathrm{R} 4$, in two cases a low bacteria count $(\mathrm{SPC}<100000 \mathrm{CFU} / \mathrm{mL}$ ) was recorded at $48 \mathrm{~h}$ during treatment, and in another three cases at the end of treatment, while a high bacteria count was observed in three cases. In all these cases, S. epidermidis was isolated from the milk before the treatment. Also, a high SCC (SCC $<200,000$ cells $/ \mathrm{mL}$ ) was observed in three cows, among which two had a low bacteria count (Fig. 2).
In the cows treated with R7, only one had a high bacteria count, and Streptococcus spp. was isolated from the milk of this cow. A low bacteria count was recorded in one cow at the third measurement, in another one at the fourth, and in five cows at the last measurement, after the end of treatment. A high SCC was recorded in two cows: the cow with a high bacteria count and another.

Similarly, among the animals treated with $\mathrm{CA}$, one presented a high bacterial count at the fifth measurement and the same animal and other two cows had a high SCC. In the milk samples belonging to the cow with a persistent high bacterial count, $S$. aureus and Aerococcus spp. were detected.

If a treatment can be considered effective when both SCC and SPC are under the maximum limit, R7 was effective in six out of eight cows, R4 in three out of eight cows, and CA in one out of four cows. However, the SCC count may take a longer time to fall to under the maximum limit since the treatments are aimed primarily at eliminating bacterial cells and the inflammation may also decrease under treatment only as a secondary effect. The selected predominant bacterial strains isolated from mastitis milk presented different values of inhibition area when tested in vitro (Fig. 2). Even with this observation being made, the $\mathrm{R} 7$ product remains the most effective, conventional antibiotics being less effective and R4 the least.

\section{Discussion}

Treatment of clinical and subclinical mastitis usually involves antibiotic administration, to clear the quarter of the causative organisms. Economic considerations require that the best possible cure should be obtained with the shortest withdrawal period of the animal, so that the milk can be marketed again (11). Antibiotic therapy cannot be detached from costs for dairy farmers. For this reason, alternative treatments are being developed, so that the final product (milk) is free of dangerous contaminants from the class of antibiotics which would otherwise be required.

The identification of different staphylococci strains in mastitic milk samples is consistent with that of other research studies (28). In our previous study (21), eight natural biological products were tested in vitro against pathogens isolated from mastitic milk. Among them, three presented inhibition areas comparable to those seen with both florphenicol and enrofloxacin and larger than those of penicillin, gentamicin, and amoxicillin (21). Because of the small number of mastitis cases available on the tested farm, only two of the natural products for mastitis treatment were included in this study. Three products with in vitro efficacy from the previous study, including the two tested in the present study, had the same natural ingredients but contained them at different concentrations. The active ingredients included aqueous extract of propolis, alcoholic extracts of Brewers Gold and Perle hops, plum lichen, common 
mallow, marigold, absinthe wormwood, black poplar buds, lemon balm, and essential oil of oregano, lavender, and rosemary. The difference between the R4 and R7 formulations as tested in the present study was a higher concentration of all the active ingredients in the latter. Although no statistically significant difference between the means of SSC and BCC among the three groups (R4, $\mathrm{R} 7$, and CA) was reported, at five days after the end of treatment, a high proportion of cows treated with R7 had both parameters under the limit (six out of eight), nearly half of the R4-treated cows (three out of eight) had such, and for the cows given CA, the proportion was a quarter (one out of four). If only the total number of bacteria are considered, in the case of R7, seven out of eight cows had good BCC in their milk, three out of four did in the case of $\mathrm{CA}$ and five out of eight for R4. These differences between BCC and SCC in the case of CA, seen against the almost non-existent difference in the cases of R4 and R7, may suggest that the gels also have a role in the reduction of inflammation. This possible effect was previously suggested for several essential oils (Nepeta cataria, Rosmarinus officinalis, and Origanum vulgare) which contain various bioactive compounds with potent anti-inflammatory effect including carvacrol, limonene, citronellal, and cinnamaldehyde (22).

Good BCC results were obtained in seven out of eight cows treated with R7. In these seven cows, the bacteria $S$. epidermidis, $S$. hominis, $S$. aureus and Bacillus spp. were detected in the milk before treatment. As indicated by BCC, after the treatment there was a decreasing of bacterial load suggesting its effect on these species. The only cow treated with R7 in which a high BCC was recorded also after the treatment had Streptococcus spp. identified in its milk, suggesting a moderate effect on this species. Similarly, in vitro testing of R7 showed good inhibitory activity on staphylococci (S. chromogenes, S. hyicus, S. intermedius, and S. xylosus), Lactococcus lactis, Kytococcus sedentarius, Bacillus cereus, and on the Gram-negative bacteria Vibrio fluvialis and Yersinia ruckeri (21). However, only moderate activity was recorded against Gram-negative bacteria such as Escherichia coli, Serratia liquefaciens, Enterobacter intermedius (Kluyvera intermedia), or Aeromonas hydrophila and A. caviae (21). The efficacy of R7 on Gram-negative bacteria was not evaluated in vivo, because these were not isolated from the milk samples from cows found positive for mastitis. However, other studies have shown good activity against Gram-negative bacteria for preparations having some of the main ingredients of our gels. For example, active compounds present in lichen extracts (in acetone, methanol, ethanol, water, diethyl ether, chloroform, and petroleum ether extraction) are bactericidal to Gram-negative microorganic pathogens like Aeromonas, Enterobacter, Helicobacter, Klebsiella, Pseudomonas and Proteus spp. (30). Similarly, ethanolic extract of propolis can be used against Gram-negative bacteria such as $K$. pneumoniae, E. coli, or $P$. aeruginosa $(1,8,26)$. An antimicrobial effect of Rosmarinus officinalis and Moringa oleifera was also recorded for Gram-negative microorganisms isolated from milk $(4,20)$. Based on these observations, by increasing the concentrations of the ingredients in the gels under evaluation, a better efficacy on Gramnegative bacteria could be obtained.

Compared to conventional therapy, the natural products used in this study (containing different plant extracts and propolis) suggest good efficacy in the treatment of mastitis caused by Gram-positive bacteria. Medicinal plant extracts appear to be a safe, efficient, and low-cost option for treating this type of disease, minimising economic losses, and equally importantly, forestalling the development of drug resistance both in animals and in humans consuming animal products. Further research is necessary to identify all active compounds of the extracts, evaluate their effectiveness, and establish different safety indices (principally the potentially toxic concentration), and so are clinical trials.

Conflict of Interests Statement: The authors declare that there is no conflict of interests regarding the publication of this article.

Financial Disclosure Statement: The study received the financial support of the (1) Project Partnerships in Priority Areas Programme - PN II, developed with the support of MEN-UEFISCDI, project no. 148/2014; (2) Programme 2: Competitiveness of the Romanian economy through research, development and innovation: PN-III-P2-2.1-CI-2018-1472 no. 252 CI from 03/09/2018. Project title: Biologically active product for controlling nosemosis in bees; and (3) Subprogramme 1.2 - Institutional Performance Projects for Financing the Excellence in CDI, Contract no. 37PFE/06.11.2018. Title of the project: "Increasing the institutional performance through consolidation and development of research directions within the USAMVCN".

Animal Rights Statement: None required.

\section{References}

1. Bačić G., Mačešić N., Radin L., Aladrović J., Matanović K., Mašek T., Brozić D., Benić M., Radić B., Bačić I., Šuran J.: Intramammary propolis formulation for prevention and treatment of mastitis in dairy ruminants (RC.2.2.08-0003). J Anim Res 2016, 6, 47-49.

2. Bhosale R.R., Osmani R.A., Ghodake P.P., Shaikh S.M., Chavan S.R.: Mastitis: an intensive crisis in veterinary science. Int J Pharma Res Health Sci 2014, 2, 96-103.

3. Blood D.C., Studdert V.P.: In: Saunders Comprehensive Veterinary Dictionary, edited by D.C. Blood \& V.P. Studdert, W.B. Saunders, Philadelphia, 1999, 1380-1381.

4. Cheng W.N., Jeong C.H., Seo H.S., Han S.G.: Moringa extract attenuates inflammatory responses and increases gene expression of casein in bovine mammary epithelial cells. Animals (Basel) 2019, 9, 391, doi: 10.3390/ani9070391.

5. Dohoo I.R., Meek A.H.: Somatic cell counts in bovine milk. Can Vet J 1982, 23, 119-125. 
6. Duarte C.M., Freitas P.P., Bexiga R.: Technological advances in bovine mastitis diagnosis: An overview. J Vet Diagn Invest 2015, 27, 665-672.

7. Erskine R.J., Wagner S., DeGraves F.J.: Mastitis therapy and pharmacology. Vet Clin North Am Food Anim Pract 2003, 19, 109-138.

8. Fiordalisi S.A.L., Honorato L.A., Loiko M.R., Avancini C.A.M., Veleirinho M.B.R., Machado Filho L.C.P., Kuhnen S.: The effects of Brazilian propolis on etiological agents of mastitis and the viability of bovine mammary gland explants. J Dairy Sci 2017, 99, 2308-2318.

9. Fourichon C., Seegers H., Beaudeau F., Verfaille L., Bareille N.: Health-control costs in dairy farming systems in western France. Livest Prod Sci 2001, 68, 141-156.

10. Gopinath S.M., Suneetha T.B., Mruganka V.D.: Chemical prophylaxis and antibacterial activity of methanolic and aqueous extracts of some medicinal plants against bovine mastitis. Int J Adv Biol Res 2011, 1, 93-95.

11. Gruet P., Maincent P., Berthelot X., Kaltsatos V.: Bovine mastitis and intramammary drug delivery: review and perspectives. Adv Drug Deliv Rev 2001, 50, 245-259.

12. Hogan J.S., Gonzalez R.N., Harmon R.J., Nickerson S.C., Oliver S.P., Pankey J.W., Smith K.L.: Laboratory Handbook on Bovine Mastitis, National Mastitis Council, Madison, 1999.

13. International Organization for Standardization: ISO 133662:2006. Milk - enumeration of somatic cells - Part 2: Guidance on the operation of fluoro-opto-electronic counters.

14. International Organization for Standardization: ISO 21187:2004. Milk - Quantitative determination of bacteriological quality Guidance for establishing and verifying a conversion relationship between routine method results and anchor method results.

15. Ivanković A., Ramljak J., Štulina I., Antunac N., Bašić I., Kelava N., Konjačić M.: Characteristics of the lactation, chemical composition and milk hygiene quality of the Littoral-Dinaric ass. Mljekarstvo 2009, 59, 107-113.

16. Kulkarni A.G., Kaliwal B.B.: Bovine mastitis: a review. Int J Recent Sci Res 2013, 4, 543-548.

17. Markey B.K., Leonard F.C., Archambault M., Cullinane A., Maguire D.: Clinical Veterinary Microbiology, Mosby Elsevier, Maryland Heights, 2013, 105-118.

18. Nascimento J.D.S., Fagundes P.C., Brito M.A.V.D.P., dos Santos K.R.N., Bastos M.D.C.D.F.: Production of bacteriocins by coagulase-negative staphylococci involved in bovine mastitis. Vet Microbiol 2005, 106, 61-71.

19. National Mastitis Council: Microbiological procedures for the diagnosis of bovine udder infection and determination of milk quality, National Mastitis Council, Verona, 2004.

20. Paşca C., Mărghitaș L.A., Dezmirean D.S., Bobiș O., Bonta V., Mărgăoan R., Chirilă F., Fiț N.: The Assessment of the antibacterial activity of some plant extracts on normal and pathogenic microflora from milk. Sci Pap: Anim Sci Biotechnol 2015, 48, 166-172.

21. Pașca C., Mărghitaș L.A., Dezmirean D.S., Bobiş O., Bonta V., Chirilă F., Matei I., Fiț N.: Medicinal plants based products tested on pathogens isolated from mastitis milk. Molecules 2017, 22, 1473, doi: 10.3390/molecules22091473.

22. Pérez S., Zavala M., Arias L., Ramos M.L.: Anti-inflammatory activity of some essential oils. J Essent Oil Res 2011, 23, 38-44.

23. Petrovski K.R., Buneski G., Trajcev M.: A review of the factors affecting the costs of bovine mastitis. J S Afr Vet Assoc 2006, 77, $52-60$.

24. Schukken Y.H., Tikofsky L., Zadoks R.N.: Environmental control for mastitis prevention, milk quality, and food safety. In: Mastitis in dairy production: current knowledge and future solutions, edited by $H$. Hogeveen, Wageningen Academic Publishers, Wageningen, 2005, pp. 109-114.

25. Sordillo L.M., Shafer-Weaver K., DeRosa D.: Immunobiology of the mammary gland. J Dairy Sci 1997, 80, 1851-1865.

26. Stepanović S., Antić N., Dakić I., Švabić-Vlahović M.: In vitro antimicrobial activity of propolis and synergism between propolis and antimicrobial drugs. Microbiol Res 2003, 158, 353-357.

27. Vliegher S., Fox L.K., Piepers S., McDougall S., Barkema H.W.: Invited review: Mastitis in dairy heifers: nature of the disease, potential impact, prevention, and control. J Dairy Sci 2012, 95, 1025-1040.

28. Wald R., Hess C., Urbantke V., Wittek T.: Characterization of Staphylococcus species isolated from bovine quarter milk samples. Animals 2019, 9, 200, doi: 10.3390/ani9050200.

29. White D.G., McDermott P.F.: Emergence and transfer of antibiotic resistance. J Dairy Sci 2001, 84 (E. Suppl.), E151-E155.

30. Zambare V.P., Christopher L.P.: Biopharmaceutical potential of lichens. Pharm Biol 2012, 50, 778-798. 